\title{
PROBLEMÁTICA MURCIA-DON JUAN MANUEL EN LA MINORÍA DE ALFONSO XI
}

\author{
Juan TORRES FONTES
}

Universidad de Murcia

Murcia y don Juan Manuel protagonizan en dos distintas fases un intenso y estridente periodo de trece años, caracterizado por la continuidad de un enfrentamiento directo que no tendrá fin hasta 1327 , y del mismo serán testigos y, en parte, actores en todo momento, desde posiciones distintas y diversidad de actuaciones, acordes por lo general en cuanto a medidas a adoptar, el infante don Pedro y Jaime II. El primero, como tutor de Alfonso XI, su sobrino, y apoyado por su madre, María de Molina, procuraría en la medida de lo posible atender las demandas de su cuñado, siguiendo las indicaciones de su común suegro Jaime II, pero, sujeto a su deber y rectitud de conducta, no pudo evitar tensas relaciones con don Juan Manuel, amistosas o enfrentadas, ante sus desafueros y permanente empleo de las armas como fuerza coaccionadora. Un perfil, en cierta forma poco novedoso, es el que ofrece Jaime II en estos catorce últimos años de su vida y reinado; el monarca aragonés, puntualmente informado de todo lo que sucedía en Castilla, actuó siempre como buen político, prudente y persuasivo, y más tratándose de un reino ajeno y de la actividad de sus dos yernos, se alejó de todo propósito de sacar utilidad política para su Corona, aunque si intentó convertirse en árbitro de las contiendas y enfrentamientos que mantenían don Pedro y don Juan Manuel, quienes, por otra parte, solicitaron más de una vez sus consejos e intervención, respondiendo Jaime II, por carta o con el envío de emisarios, siempre desde la óptica familiar y empleando un tono paternalista que sólo buscaba el entendimiento y fraternal conexión entre sus yernos. Tampoco faltó correspondencia con doña María de Molina y con el infante don Juan con quienes estaba unido al compartir el mismo deseo de hallar una fórmula que fuese acomodaticia para todos y que trajera, con ello, la paz al reino castellano.

Sin embargo, pese a lo dicho más arriba, conviene esclarecer ahora que el rey de 
Aragón no mantenía la misma relación con el infante don Pedro que con don Juan Manuel. Era más comprensible y cercana la actitud de Jaime II con el infante castellano, tanto como tutor y representante de la autoridad real, como por compartir sus ideas de gobierno e incluso su actividad en la frontera granadina, que tan intensamente atraía a don Pedro. Muy distinta y forzosamente diferente será la que muestre hacia don Juan Manuel, personaje eternamente descontento, rebelde, engañado y desengañado, cuyas imprudencias y malas hechuras recriminaría con dureza en más de una ocasión, aunque, es verdad, siempre utilizando el paliativo de esforzarle en la atención de la mesura, de la paz y del entendimiento con su cuñado, cosa muy beneficiosa para él y para el bien del reino castellano.

En este breve espacio de trece años, que comprende la menor edad de Alfonso XI, en lo referente al orden cultural no contamos con datos suficientes para hacer nada más que dos menciones concretas, pues la situación de Castilla no propiciaba una producción literaria cualificada ni otras manifestaciones de alta valoración. Una es la de don Juan Manuel quién, como últimamente ha dicho Germán Orduña, sólo debió redactar dos obras en estos años: la Crónica Abreviada y el Libro de la Caza, ambos productos obtenidos a base de inspirarse en fuentes alfonsíes. La segunda obra sería reformada tiempo después con una nueva redacción, con lo que adquiriría los procedimientos expositivos de don Juan Manuel en su segunda etapa creativa y, para entonces, de mucha utilidad fue el conocimiento personal que el señor de Villena tenía de todo el Reino de Murcia y restantes posesiones con su variedad de caza, parajes donde abundaba, especies y formas de captura.

Un aspecto a destacar desde los primeros años de su relación con el Reino de Murcia, y que parece oportuno traer aquí, sería la educación muy cuidada que debió recibir y que él mismo consideraría como la más conveniente para los hijos de los nobles: «desque pasaren de cinco años adelant, deven començar poco a poco a les mostrar leer... e este leer deve ser tanto a lo menos fasta que sepan fablar et entender el latin». Todo ello está directamente conectado con su propia experiencia, pues sabemos que a los cinco años era adoctrinado en Elche, que para él era "como regno e señorio apartado... a manera de reyes», por un maestro de Gramática quién, cuando se lleva a efecto la Quinta Partición en el Repartimiento de Orihuela, en Febrero de 1288 , recibe "LX atafullas en Cox, en las fronteras, por rogos et por carta de la condesa et de don lohan, so fijo, et del infante don Manuel». Quedamos sin conocer la identidad del maestro de Gramática que se dedicaba a enseñarle con paciencia, halagos y perseverancia sus primeras letras; se trata de uno de los muchos secretos que don Juan Manuel nunca desveló, como tampoco se conocerán sus lecturas posteriores de las fuentes clásicas, que bien cuidó de ocultar, y esa misma ignorancia tenemos en el protagonismo que pudo tener entonces, como indica Lomax, «una madre italiana cuya influencia sobre el gran escritor queda por calibrar».

Solamente otra figura destaca en el ámbito murciano en estos primeros años del Siglo XIV y es la del historiador Jufré de Loaysa, autor de una "Crónica de los Reyes de Castilla» que, si bien no alcanza en su narración estos años de la minoría de Alfonso $\mathrm{XI}$, si nos dejó una imagen precisa de Castilla la cual, sin variante alguna, cabe 
reproducir como reflejo de cuanto sucedería en estos trece años: «Entonces joh dolor! ningún mercader ni hombre honrado transitaba por Castilla, ni el pastor guardaba sus ganados, ni el buey araba la tierra, sino que las llanuras estaban desiertas, los caminos solitarios, cubiertos de hierbas y frecuentados por liebres más bien que por ganados. Y los hombres no gustaban otra cosa que de muertes, robos y despojos, y muchos que antes solían ganarse el sustento como artesanos o agricultores, convertidos ahora en guerreros, despojaban a cuantos podían, robaban, pasaban a fuego los poblados y ya no se respetaba lugar sagrado, sexo ni edad $u$ orden».

\section{LA DUALIDAD CONCEJO-HERMANDAD DE MURCIAY DON JUAN MANUEL (1313)}

El 9 de Septiembre de 1312 muere Fernando IV y se esfuma el precario orden político logrado algunos años atrás con el inicio de la menor edad de Alfonso XI que comienza con la renovación de un problema que ya se había planteado en la minoría de su padre y que era la falta de una legislación, norma o costumbre afianzada respecto a quien o quienes debían desempeñar la tutoría del monarca. Don Juan Manuel se encontraba en Murcia y tan pronto tuvo noticia del deceso del rey, de quien era mayordomo mayor, se apresuró a marchar a su señorío de Villena con el propósito de dirigirse después a Toledo y permaneciendo a la expectativa de todo lo que pudiera producirse en torno a Alfonso XI, con el firme propósito de hacer valer su alto rango, su pertenencia a la familia real, cuanto había significado su desempeño de la mayordomía mayor del rey, sus posesiones, riqueza y poder. En este contexto, más rápido fue el infante don Pedro quién, atisbando la inevitable confrontación política que iba a producirse en todo el reino castellano, desde Andalucía marchó hacia Toledo y, desde Yébenes, escribía a don Juan Manuel solicitándole con todo fervor su ayuda para conseguir la tutoría de su sobrino y ofreciéndole firmes promesas de futuro como modo de agradecer sus servicios y, días después, desde Ávila, volvía a expresarle su agradecimiento por la seguridad de ayuda que le ofrecía su cuñado.

Promesas y apetencias por ambas partes que habrían de concretarse en la entrevista concertada en Valladolid, el día 8 de Noviembre, entre el maestre de Calatrava, enviado con plenos poderes por el infante don Pedro, y don Juan Manuel. En ella el ofrecimiento del infante era tan generoso y la ambición de don Juan Manuel tan extremada, que sólo un incauto pudiera creer que se hicieran efectivas. Eran éstas: «Que vos tengades en guarda por el dicho rey don Alfonso el regno de Toledo et el regno de Murcia et los obispados de Cuenca et de Siguença, et que ayades y el mismo poder que el dicho infante ouier en lo que fuese tutor, a tanto tienpo como el dicho infante don Pedro terna la dicha tutoria et usara della». Once días más tarde se congratulaba Jaime $\|$ de este acuerdo entre sus yernos y escribía a don Juan Manuel felicitándole y animándole a perseverar en el acuerdo por el bien de Castilla.

Mientras tanto, con formaciones ya públicamente declaradas, el infante don Juan asumía el poder en el Reino de León y proclamaba, frente a don Pedro, su propósito de ser también tutor del monarca, a la vez que doña María de Molina cuidaba de su nieto y procuraba aquietar el reino y concertar una concordia que impusiera la paz. 
Seis meses más tarde, el 23 de Mayo, don Juan Manuel denunciaba ante Jaime II la actitud de don Pedro, ya que percibía que las buenas palabras y promesas eran sólo eso y que no tendrían efectividad, tal y como la misma Maria de Molina se lo había hecho ver a la vez que le advertía de que su intención era que ambos infantes se compenetraran y gobernaran los reinos que los aceptaban. Esta vez Jaime II intervino cerca del infante don Pedro y consiguió arrancarle la promesa de poner en manos del arzobispo de Toledo la solución a sus diferencias y recobrar la amistad y confederación perdidas.

El desorden, anarquía, robos, muertes y destrucciones que se extendieron por toda Castilla no tardarían en exigir un resurgimiento de las Hermandades concejiles como único medio de autodefensa; pero, a diferencia de las que se configuraron en 1282, éstas pronto perdieron su independencia por la participación en ellas de la nobleza, ávida de hacerse con el poder. Sin embargo, no sucedió así en Murcia, en donde la Hermandad surge con el firme propósito de sus vecinos de romper el oneroso trato que soportaban de don Juan Manuel y sus vasallos; y tampoco iba a ser una Hermandad en la que se integrarían los demás municipios del reino, como en el Siglo XIII, sino organizada exclusivamente para recobrar su independencia y disfrutar de su fuero y privilegios. En realidad, la sucesión de vejámenes, ocupación de todos los oficios concejiles, exceso de cargas financieras, parcialidad de la justicia y atropellos de todas clases no dejaban otra salida y fueron el detonante de la Hermandad y de los sucesos acaecidos en la capital del adelantamiento murciano.

En fecha anterior a Julio de 1313 se produjo el asalto y parcial destrucción del alcázar de Murcia, puesto bajo el mando de Sancho Manuel, detenidos y después expulsados de la ciudad cuantos partidarios de don Juan Manuel se encontraban en ella. La revuelta debió de ser violenta y la hostilidad se mantuvo por cuanto los «fuera echados", refugiados en Molina Seca, comenzaron a hostigar a todos los que permanecían en la capital, alcanzando los enfrentamientos y acciones gran virulencia y llegando a preocupar a los propios gobernantes oriolanos, como lo prueba que, en el mes de Julio, Arnau de Torrelles pidiese autorización a Jaime II para reforzar la vigilancia de las puertas de Orihuela en prevención de las posibles secuelas de la contienda murciana que pudieran llegar hasta ella.

De la situación se hizo eco Jaime II cuando, en Diciembre, amonestaba a su yerno por su conducta: «lo de Murcia nos pesa si algo an feyto no deuidamente encuentra uos. Enpero, sabedes muy bien que Murcia del Rey de Castilla es e, al tienpo que esta agora la tierra, muyto devriades conpensar et non faser ante ellos todo lo que podriades, mas catar servicio del rey e a sosiego de la tierra». La amenaza de don Juan Manuel de ir poderosamente contra Murcia se disipó por la prudencia del rey de Aragón, que estaría al tanto de las causas de la revuelta, tal y como fueron expresadas y justificadas en carta real del año 1317 del infante don Pedro: «Despues que el rey don Ferrando, mio padre, fino aca, que auie y algunos omnes buenos que los pasauan contra las cartas et franquezas et preuillegios et buenos usos et costunbres que auian en tienpo de los reyes onde yo vengo. Et, otrosi, que se mouian a fazer posturas et ordenamientos et usos et costunbres nueuamiente, que nunca fueron, que eran et son contra ellos et contra los dichos sus preuillegios". 
Reconocimiento de la imposibilidad de ganar Murcia por la fuerza sería la firma de una concordia entre Murcia y Cartagena con su castillo. Esta ciudad pasó poco después de 1306 a propiedad de Pedro López de Ayala, alférez y lugarteniente de don Juan Manuel a quien, en Diciembre de 1313, según el "Chronicon Domini Joannis Enmanuelis», la vendió con ciertas condiciones que no se especifican, pero, sin duda, una de ellas serían los plazos para su pago, que terminaría de efectuarse en 1325, tal y como señala el mismo "Chronicon» cuando dice: «En el mes de Junio don Joan pago del todo a Pedro Lopez de Ayala: la deuda que era tenido por razon de la ciudad de Cartagena y dicha ciudad quedo a don Joan sin condicion». La concordia MurciaCartagena se firmaría el 5 de Enero de 1314 y en ella se otorgaban mutua seguridad para personas, ganados y mercancías; obligada salida en apellido para perseguir a malhechores y, por ambas partes, se fijaba una cláusula por la que se estipulaba que si el infante don Pedro no aceptaba este convenio, hecho público, se mantendría por diez días, lo mismo que sucedería por parte de Cartagena y su castillo en la obediencia a don Juan Manuel. Siendo significativo que se incluyan autoridades dependientes de ambos nobles denominados por cada uno de ellos como «nuestro adelantado", indicativo de una situación de separación oficial de la ciudad de Murcia con respecto a su anterior dependencia de don Juan Manuel, que había sido adelantado del reino en el reinado de Fernando IV.

\section{CONTINUIDAD DIFERENCIADORA (1314-1319)}

Las promesas no cumplidas por los tutores de Alfonso XI y la constancia murciana en su negativa a reconocer a don Juan Manuel como adelantado, eran afrentas permanentes que llegarían a exasperar al señor de Villena de tal modo que, sin pensar en sus posibles consecuencias, amenazó a Murcia con permitir el paso libre por Lorca de los granadinos. Pedro López de Ayala, alcaide de Lorca por don Juan Manuel, fue el encargado de comunircarlo así a la Hermandad de Murcia: O se sometían a don Juan Manuel o Murcia quedaría fuera de la tregua que tenía firmada con Ismail de Granada.

El concejo de Murcia recurrió al infante don Pedro y, como en ocasiones anteriores, confiados en la buena acogida que siempre habian encontrado, a Jaime II a quien hicieron saber la amenaza que pesaba sobre ellos. La respuesta del monarca aragonés fue inmediata y escribió a su yerno para hacerle ver que tal amenaza no era buena manera para atraer a los de Murcia a un posible entendimiento y sobre todo para inducirle a pensar en la "carga e infamia vuestra a Dios y al mundo», así como en el escándalo que iba a producir. Escribió también a Murcia para exponer sus dudas: «Sabe Dios si el noble don Johan, fijo del infante don Manuel, ha fecho ni faze ninguna cosa contra vos". Una tercera misiva o emisario envió a Arnau de Torrelles, Procurador General de Orihuela, a quien expresaba su desconfianza de los que pudiera hacer su yerno y le ordenaba que enviase a su lugarteniente, Berenguer de Puigmoltó, con hueste suficiente a Murcia para ayudarles a hacer frente a los posibles ataques granadinos. 
Esta decisión irritó a don Juan Manuel, que no tardó en quejarse a su suegro por el perjuicio que le ocasionaba al consolidar con su actuación la actitud de la Hermandad murciana de no recibirlo por adelantado. Jaime II contestó de inmediato y le dejó bien claro que no lo había hecho por mala voluntad hacia él, sino por «celo de buen amor», indicativo de su propósito de evitar que la torpeza del señor de Villena tuviera efectividad y le perjudicara. $Y$, aún más, su inoportunidad, pues le anunciaba que el infante don Pedro le enviaría un emisario para notificarle el acuerdo de Palazuelos, firmado el 1 de Agosto, por el que se constituía la regencia de Alfonso XI así como el reconocimiento de las respectivas áreas de gobierno, por lo que sería el infante castellano quien podría resolver la contienda que mantenía con Murcia.

Mas, no iba a ser así. Informado don Pedro de la amenaza contra la ciudad de Murcia y las medidas adoptadas por Jaime II, desde Toro atendió la reiterada petición de la Hermandad referente a que les proporcionase un jefe adecuado para que la acaudillara y al frente de su hueste se enfrentase a los granadinos. El 16 de Noviembre Diego López de Haro recibió su nombramiento como adelantado de Murcia e instrucciones precisas de don Pedro para trasladarse a Murcia y poner manos a la obra, cosa que hizo al poco tiempo, pues el día 7 de Diciembre llegaba a su destino portando tres cartas que, al día siguiente, domingo, presentó ante un concejo abierto, totalmente expectante por la llegada de un adelantado que no era delegado de don Juan Manuel. Aparte del documento que contenía su nombramiento, López de Haro mostró la carta por la que don Pedro concedía las escribanías de la ciudad al concejo y, otra tercera, datada en Toro el día 15 de Noviembre, por la que el infante, atendía la petición que Murcia le había formulado para que donase Molina Seca como aldea de la ciudad, tal y como había sido en el reinado de Alfonso X, pues se había convertido, como dice Cascales, en «una ladronera de forajidos», en reducto armado de la gente de don Juan Manuel y desde ella se hacían considerables daños a los vecinos de la capital, por lo que don Pedro indicaba que debían "punnad por quantas partes pudierdes en la ganar... que si uos ganades, que uos la dare». El mismo Cascales nos dice que la hueste murciana pudo ocupar la villa con facilidad por encontrarse desprevenidos sus defensores, tras lo cual fueron expulsados cuantos en ella se hallaban.

Al finalizar 1314 una triple perspectiva de carácter negativo pesaba sobre don Juan Manuel: desconfianza de sus actos y correctivos de Jaime II; recelo y continuidad de falsas promesas de don Pedro y, más que reticencias, enemistad irreductible de la ciudad de Murcia. Ahora el hijo del infante don Manuel buscaría de nuevo la imponderable ayuda del rey de Aragón y, a través de él, la de su cuñado, con objeto de conseguir unos logros que tercamente solicitaba: nombramiento de mayordomo mayor, reintegración del adelantamiento de Murcia con sus rentas y libre entrada de sus vasallos en la capital.

Jaime Il logró persuadir a sus yernos para que acudiesen a una reunión, convocada en Uclés para Enero de 1315, con objeto de alejar dudas, recelos y reticencias. Don Pedro se comprometió a escribir a Murcia y ordenar que recibieran a don Juan Manuel, con promesa de su «segurança» y sin temor a venganzas o represalias; pero, conocedor de la repulsa murciana y no muy decidido a llevar adelante lo convenido, 
trasladó a su suegro la resolución de esta cuestión y le pidió que enviase un emisario a Murcia para que intentara la avenencia y les amenazara con exigir la salida de territorio aragonés de ganados, bienes y personas, así como la prohibición a sus súbditos de toda relación con ellos. La negativa murciana se mantuvo en términos tan tajantes que Pedro Garcés de Castellón, enviado por Jaime II, a su vuelta informó al monarca de la total imposibilidad por entonces de hacer cambiar de opinión a la Hermandad murciana.

La persistente actividad granadina uniría a murcianos y oriolanos para la consecución de acciones conjuntas, aunque sin carácter oficial por la prohibición del rey aragonés, bajo la jefatura de Berenguer de Puigmoltó y del adelantado Diego López de Haro y sin la participación de Pedro López de Ayala, alcaide de Lorca por don Juan Manuel. Quizá la actitud de éste motivaría la carta del infante don Pedro, fechada el 10 de Marzo, alarmado por las noticias que le llegaban desde el reino de Murcia referentes a que algunos no respetaban la tregua firmada con Granada.

En las Cortes de Burgos de este mismo año 1315 fueron aprobados los conciertos de Palazuelos y declarados oficialmente los tutores de Alfonso XI, produciéndose el nombramiento como mayordomo mayor a favor de un hijo del infante don Juan y como adelantado mayor de Murcia a don Juan Manuel. En las Cortes ocurrió un hecho insólito, por cuanto fueron confirmados los fueros y privilegios de todo el reino castellano con excepción de los de Murcia, recabada por don Juan Manuel. La cuestión Rocafull, que se produjo por entonces, alejaría del ámbito cortesano el problema murciano.

Ya en 1316, el infante don Juan logró reconciliar a los enfrentados cuñados, sin nuevas medidas referentes a Murcia, mientras que las relaciones murciano-oriolanas se hacían cada vez más estrechas, hasta el extremo de que Berenguer de Puigmoltó, lugarteniente de Procurador, acudiera ante Jaime II en apoyo de algunas peticiones murcianas y, así, pudo obtener autorización para la saca de armas, hierro y otras mercaderías procedentes de Mallorca cuyo destino oficial era Castilla, pero que, muy probablemente, no saldrían de la frontera murciana y sin duda este suceso se encuentra muy relacionado con la actividad fronteriza frente a los granadinos.

La constancia de don Juan Manuel en reivindicar el adelantamiento y la insistencia de Jaime II en que hubiera una buena relación entre ellos, forzaría a la orden de don Pedro para que fuese aceptado don Juan Manuel, ya nombrado adelantado, y lo que de ello se derivaría, y en caso de negativa concedía autorización a éste «et a todos los concejos de las sus comarcas que los maten et les tomen quanto les fallaren de lo suyo". Pero la actitud de Murcia no cambiaba y el rey de Aragón comunicaba, el 18 de Febrero, a la corte castellana que el concejo murciano se mantenía intransigente, por lo que mandaba a su Procurador de Orihuela que diera un plazo de ocho días para que los vecinos de Murcia salieran de sus tierras con sus pertenencias. Sin embargo, como sucediera dos años antes, esta medida no tendría efecto por la protesta oriolana, más perjudicada, lo que obligaría a dejar en suspenso la orden mediantes sucesivas ampliaciones de plazos; pudiéndose advertir la continuidad de un equívoco entre órdenes oficiales y particulares, en que parecen estar todos involucrados: Jaime II, el 
Procurador de Orihuela, el Infante don Pedro y las autoridades murcianas en espera de otros acontecimientos.

Mientras se mantenían estos escarceos políticos y la polémica Murcia-don Juan Manuel, la frontera murciana seguía activa, en tanto que la división del reino debilitaba sus fuerzas, pues el infante don Pedro operaba en sectores alejados y López de Ayala veía reducida la hueste que guarnecía Lorca. En una incursión fue derrotado y quedó comprometida la fortaleza lorquina por estar "la gente muy esmayada" y con el temor de que los granadinos intentaran ocupar la ciudad, panorama que permaneció hasta que, dos meses más tarde, acudió don Juan Manuel y restableció la situación. El triunfo del señor de Villena fue aprovechado por Jaime II para hacer ver a los tutores de Alfonso XI la necesidad de que don Juan Manuel permaneciera en la frontera con todas las fuerzas murcianas bajo su mando; pero, muy pronto, el veleidoso titular del señorío de Villena se excusó de mantenerse en ella por haber pasado el tiempo en el que sus vasallos obligadamente le prestaban sus servicios y no tener medios propios ni facilitárselos la corte o no contar con la ayuda pontificia.

Frente a ello, se produjo un nuevo cambio en la actitud política del infante don Pedro quién, antes de finalizar el año 1317, atendía las demandas murcianas que denunciaban que hasta 1313 habían estado sometidos a decisiones injustas de vasallos de don Juan Manuel, hombres adictos a su persona que formaban un concejo reducido: los oficios de alcaldes, alguaciles, jurados y almotacenes eran designados por el adelantado, promulgación de ordenamientos y nuevas disposiciones contrarias a su Fuero, privilegios, usos y costumbres, no confirmados en las Cortes de Burgos. No desconocía don Pedro esta situación y las justas pretensiones murcianas, por lo que, dispuesto a atender sus peticiones, desde Ubeda, el 8 de diciembre de 1317, les confirmaba su Fuero y privilegios en nombre de Alfonso XI.

Este vaivén de alternativas contradictorias entre la rectitud de don Pedro y la decisiva influencia de su suegro por atender las reclamaciones de don Juan Manuel, le haría cambiar de nuevo su política respecto a Murcia. Jaime II pudo lograr que sus dos hijas y yernos se reunieran en Ocaña corriendo el mes de Enero de 1318, y en este ambiente familiar aunque un tanto forzado por las circunstancias, don Pedro autorizó de nuevo el empleo de la fuerza para que el señor de Villena intentara someter a los rebeldes murcianos. En el mes de Julio se produjo un encuentro armado del que no parece que salieran muy airosas las huestes del señor de Villena y sin que por ello adelantara en sus pretensiones para ser aceptado.

Al empleo de la fuerza siguió la diplomacia encaminada a hallar una vía pacífica con la que se llegase a la armonía y al entendimiento. El infante pidió a la Hermandad de Murcia que enviase dos «personeros» para tratar con los tutores de Alfonso XI sobre las cuestiones planteadas y alcanzar un acuerdo definitivo. La reunión se celebró en San Esteban del Puerto durante el mes de Mayo de 1319, y don Pedro, una vez llegado el consenso, no tardó en dirigir una carta a Murcia por la que notificaba el acuerdo adoptado y exigiendo su cumplimiento, al tiempo que, en esta densa misiva, especificaba que garantizaba la seguridad de todos los vecinos frente a cualquier represalia de los expulsados de Murcia; perdón y olvido de todo lo pasado; reconoci- 
miento de la legalidad de cuanto se había realizado por los alcaldes, alguaciles, jurados y almotacenes en el desempeño de sus oficios; aceptación de las sentencias de los alcaldes, salvo que hubieran sido dadas contra el Fuero o contra derecho; también quedaban aceptadas las justificaciones presentadas sobre las recaudaciones de las rentas y su gasto, así como la renta de sacas; se dejaban sin efecto ni valor los juramentos, ordenaciones y posturas que entre sí hubieran hecho para no recibir a don Juan Manuel y a sus vasallos, quitos de toda infamia o cualquier otra acusación. Tan sólo no aceptaban su petición de que los pleitos de primera y segunda alzada no conclusos, los terminaran los alcaldes que los habían iniciado.

Con esta larga carta volvieron los "personeros" a Murcia y la presentaron en el concejo abierto convocado para la ocasión, el cual rechazó todas las propuestas del infante castellano por considerar que la aceptación de don Juan Manuel supondría una vuelta atrás y restablecer la situación de 1313, precisamente aquella que motivó la rebelión contra sus «demasías» y, aún más, por el temor de que, pese a todas las promesas, no tardarían en manifestarse los propósitos de revancha y violencia de aquellos que durante siete años habian estado fuera de la ciudad tras haber sido expulsados violentamente de ella.

Siete días más tarde Jaime II expresaba públicamente su pesar por el fracaso de esta nueva propuesta y transmitía a don Juan Manuel su preocupación por cuanto podía hacer, el "enantamiento que entendedes fazer contra ellos porque non uos reçiban por adelantado». Nada haría, entre otras cosas, porque los acontecimientos cambiaron por entero la política castellana.

\section{INQUIETUD, ACTIVIDAD Y CONTRADICCIÓN FRONTERIZA CON GRANADA}

No falta en este breve período histórico de la minoría de Alfonso $\mathrm{XI}$, de división de poderes y debilidad bélica castellana, la obligada referencia, que podría llenar muchas páginas, a la frontera granadino-murciana, siempre activa, amenazante y también perenne factor político-bélico en los enfrentamientos nobiliarios castellanos, cosa que también sucedia en el Reino de Granada, sometido a una continuada guerra civil. El apoyo del infante don Pedro a Nasr, la particular relación de don Juan Manuel con Ismail y su posesión de Lorca, así como las indecisiones de Jaime II que soportaba frecuentes incursiones en territorio oriolano, dejaban la frontera en débiles condiciones de defensa y sería paso fácil para las huestes de Ismail que penetraban por territorio murciano y se plantaban en Orihuela.

Las rupturas de las treguas daban argumentos para las incursiones de fuertes contingentes en una u otra dirección, encaminadas a intentar la ocupación de castillos próximos a la línea divisoria -en 1324 se pierden Huéscar, Galera y Orce, antes el infante don Pedro había ganado Rute, Cambil, Alhabar, Bélmez, Tiscar-y en otras de castigo para asolar el territorio y ahuyentar a los pobladores lejos de ella. Tampoco la firma de treguas impedía la continuidad de estas incursiones, si bien en menor número de combatientes, que se adentraban en busca de botín, más siempre por parte granadina que murciana u oriolana. María Teresa Ferrer nos informa de la repetición 
de estas penetraciones, como la que tuvo lugar en 1314 que supuso la pérdida de 20.000 a 25.000 cabezas de ganado, y que continúan incesantemente en los años siguientes. Frente a ellas, como réplica, se conjuntaron huestes de Orihuela y Murcia a las órdenes de Berenguer de Puigmoltó y del adelantado López de Haro aunque sin mucho éxito, pero mucho peor fue la derrota de Pedro López de Ayala, lugarteniente de don Juan Manuel, que supuso unas fuertes bajas por muerte o cautiverio y que dejó en precaria situación a Lorca hasta que el propio don Juan Manuel, como hemos dicho, pudo hacer desaparecer la persistente amenaza que se cernia sobre el bastión lorquino.

Como exponente de cual era la situación, un documento de 1308, también publicado por la misma investigadora, en el que se relata un suceso que, aunque acaecido años antes de este período que tratamos, no cabe duda que fue uno más y semejante a los muchos que se contabilizan en los cuarenta años siguientes. Según versión del Deán del cabildo catedralicio murciano, entre 30 y 40 granadinos, dirigidos por un hijo del caudillo Zaen, penetraron por el término de Sangonera, a unos 6 kilómetros de Murcia, el 26 de Marzo muy de madrugada, de modo que, cuando había salido el sol, ya tenían recogida una gran presa que el eclesiástico calculaba entre cien y ciento cincuenta cabezas de ganado mayor y cinco a seis mil ovejas y carneros. El comentario del emisario aragonés a Jaime II era que más se hubieran llevado si la niebla no hubiera sido tan densa que les impedía divisar el ganado, ni ver por donde iban; y entre lo que se llevaban y más pesaba al Deán — «mal pecado» fueron sus palabraseran los seiscientos carneros pertenecientes al diezmo eclesiástico.

No hubo hombre, jinete o peón, de Murcia que no saliera en apellido a perseguir a los almogávares, incluso los de la alta clerecía, todos camino de Lorca en donde, al día siguiente, se les agregaron unos 800 hombres de la ciudad. La persecución tuvo éxito y los granadinos fueron alcanzados antes de sobrepasar la extensa zona fronteriza y en el enfrentamiento murió el hijo de Zaen, el adalid granadino para quien no falta un elogio "por ser mançebo nunca vieron un cavallero mas esforçado en una fazienda, ca si entrara por ellos como si fueran ovejas, e de mientre que el se tovo, toda su gente fazian maravillosamente». Un afortunado tiro de ballesta dio con él en tierra y su compañía fue derrotada, con lo que pudieron recuperar el ganado lanar en el que se incluían los seiscientos carneros del diezmo eclesiástico, aunque no sucedió lo mismo con las vacas y yeguas, cuya mayor movilidad les había permitido adentrarlas en territorio granadino. La cabeza del hijo de Zaen sería presentada en Murcia en señal de triunfo y para celebrar la hazaña.

La muerte de los infantes don Pedro y don Juan en la vega de Granada y consiguiente derrota del ejército castellano, no sólo dejó indefensa la frontera, sino que la desmoralización fue grande y, si no tuvo graves e inmediatas consecuencias, fue gracias a la actitud de los concejos andaluces que pudieron firmar una tregua por 8 años, lo mismo que hacía, en 1321, Jaime II al acordar una suspensión de las hostilidades con Granada por espacio de 5 años; pero tanto en una como en otra quedaba fuera el Reino de Murcia, en espera de la decisión de don Juan Manuel, invitado a suscribir la firmada por las ciudades andaluzas. 
Según informaciones de enviados aragoneses, Pedro López de Ayala trataba en Granada la consecución de una tregua para el Reino de Murcia, pero con unas condiciones tan perjudiciales para Aragón que Jaime II, al conocerlas, no pudo por menos que calificarlas de inicuas, ofensivas a Dios y en vituperio de su monarca. Debieron de circular urgentes emisarios aragoneses y la tregua Granada-Murcia se fijaría en los mismos términos normales que las establecidas con Castilla y Aragón. No por eso la frontera quedaría pacificada.

\section{EL «RIEPTO»DE GUILLÉN DE ROCAFULL}

El 1315 se produjo un estridente escándalo que afectó personalmente el honor de don Juan Manuel, conmovió a la corte y nobleza castellana y alcanzó también a la aragonesa. Fue el reto, con denuncia de hechos graves y calificados con duros denuestos aún más estruendosos por don Guillén de Rocafull, señor de Abanilla, ante los tutores de Alfonso XI, a través de cuya Crónica y las cartas publicadas por Giménez Soler permiten conocer las causas y final. Dice la Crónica «andaba don Guillén de Rocafuy diciendo mal et reptando ante el rey a don Joan, fijo del infante Don Manuel, porque decia que le prendiera".

De una anterior y amigable atención de Rocafull con el señor de Villena, pasó todo a una enemistad profunda y duradera que les enfrentaría hasta la muerte. La prisión y cuanto pudo pasar, impulsó al señor de Abanilla a retarlo públicamente en la corte castellana, exponiendo los agravios y tachándolo de cobarde y otros denuestos propios de estos casos, que según los tutores del monarca "auia dicho ante ellos algunas palabras contra don Johan que eran deshonrra de don Johan». Tan injuriosos debieron ser los improperios que el propio infante don Pedro, tutor del rey y también cuñado de don Juan Manuel, airado, ordenó la detención de Rocafull.

Pero si las acusaciones y palabras malsonantes contra el señor de Villena pudieron ser desmedidas, la orden del infante fue considerada como desafuero por la nobleza «por toda la hermandad de la caualleria de Castilla», quienes afrontaron a don Pedro haciéndole patente que el cargo que tenía no le permitía detener a Rocafull y que estaba obligado a oirle, conforme la costumbre de Castilla. Así lo hubo de hacer el tutor del rey: dejar en libertad a don Guillén y mantener el proceso en la corte.

A la natural soberbia de don Juan Manuel se sumó la ira cuando tuvo noticias de la escandalosa denuncia del señor de Abanilla y su única solución, como tantas otras veces, sería acudir a su suegro y exponerle que, según su parecer, no era uso en la corte castellana oír tales palabras y, en el obsesivo orgullo de su linaje, añadía que los tutores de Alfonso XI no habían tenido en cuenta quién era él y quién don Guillén de Rocafull. Miguel Pérez de Arbe, emisario de Jaime II, se presentó ante los tutores castellanos y les expuso la consternación de su soberano y su deseo de encontrar solución satisfactoria para su yerno; además el representante del rey de Aragón debía informarse si el caso era desaforado y si, caso de no serlo, se mantuviera la acusación, exigir seguridad para que don Juan Manuel pudiera contestar el reto y exponer sus razones. Jaime II se equivocaba al creer que todo seguiría adelante, porque su 
intervención no favorecía a su yerno al dejarle en evidencia, lo que después se llamó cobardía.

Aceptada la denuncia de Rocafull y no pudiendo suspender el proceso, todos quedaron expectantes a la espera de los acontecimientos y, reiterado el reto por. don Guillén, en el mes de Octubre, sólo quedaba atender la presencia de don Juan Manuel en la corte. De no hacerlo, su honor quedaría maltrecho y, si lo hacía, todo derivaría, según el fuero de Castilla, en un encuentro personal que debía de hacerse públicamente. Contaba don Juan Manuel 33 años y una edad semejante debía tener Rocafull, del que sabemos que en 1308 vivía su padre, y que en 1321 había enviudado y volvería a casar años más tarde. La Crónica alfonsí cuenta como, en fecha cercana, cumplido el plazo de un reto, en la lucha que dos caballeros mantuvieron en Valladolid, mató el «reptador al reptado».

La reina María de Molina, atenta a la inquietud de Jaime II, le escribiría para decirle la inutilidad de sus esfuerzos para disuadir a don Guillén, quién le decía que fueron tantas las cosas "desaguisadas" que hizo contra él, que no podía perdonar ni olvidar; Jaime II contestaba pidiendo seguridad para su yerno de todo peligro para que pudiese marchar a la corte y responder al reto. Los tutores, deseosos de encontrar una solución propicia, por cinco veces prometieron la seguridad solicitada e incluso el infante don Juan ofreció enviar a sus hijos y mil caballeros para que acompañaran al señor de Villena en el viaje, mientras que por su parte, el enviado aragonés, aseguraba a don Jaime que si don Juan Manuel buscara la ayuda de su cuñado, el infante don Pedro le sacaría del mal paso, pero, y son sus palabras, «si esto non se fase creo lo ent sacaran mal si el non responde como deue e si responde aversa a combatir su cuerpo al suyo, segunt costumbre de Castiella». Tal y como indicaba Miguel Pérez de Arbe, sería don Pedro quien ayudaría al señor de Villena a salir lo mejor posible del trance ya que, como dice la Crónica: «troxieron pleytesia con el que non pareciese a los plazos de los pregones et dio el rey por quito a don Joan».

No fue el final. Don Juan Manuel guardó un odio permanente contra Rocafull, una afrenta que no podría olvidar y, cuando cinco años más tarde, alcanza la regencia de Alfonso XI ordenó un proceso en la corte contra Rocafull y su ingreso en prisión. Pero, precavido, don Guillén salió de Castilla e hizo pleito-homenaje a Jaime II por Abanilla reconociéndole como soberano y, para tener una mayor seguridad, hizo donación oficial de su señorío a la Orden de Calatrava. Todavía habría otras vicisitudes posteriores, entre ellas la acaecida en 1327 cuando Alfonso XI incitó a Rocafull para que tomase venganza de los daños y perjuicios que le había ocasionado don Juan Manuel en los años que ejerció la tutoría.

\section{DON JUAN MANUEL. TUTOR DE ALFONSO XI Y ADELANTADO DEL REINO DE MURCIA (1320-1325)}

La inesperada y desastrosa muerte de los infantes don Juan y don Pedro el 24 de Junio de 1319 en la vega de Granada, ocasionó una nueva crisis de gobierno en Castilla, donde había quedado sola doña María de Molina, y significó también la apertura de 
nuevas perspectivas para las insaciables aspiraciones de don Juan Manuel. A ello le alentaría Jaime II tan pronto como supo lo sucedido y, prudentemente, asesoraba a su yerno pidiéndole moderación y a la vez eficaz actividad, haciendo valer «qui sodes e de qual lugar venides... e que Dios vos aya que gradescer ende... ayades buen nonbre e buena fama por el mundo». Días más tarde, el 26 de Julio, le felicitaba por su propósito de asegurar la frontera granadina y, de nuevo, le recomendaba prudencia y le estimulaba a participar en la regencia de Alfonso XI: "si la voluntad fuese de Dios et de las gentes que vos venga de governar los regnos, mucho mejor poderdes servir a Dios et al rey en la frontera et cumplir el buen talant que avedes». El envés de esta nueva situación para don Juan Manuel iba a ser la que se presentaba al concejo de Murcia, muerto don Pedro y falto del apoyo moral, político e incluso bélico que años antes había encontrado en Jaime II, quien en estas circunstancias prestaba toda su ayuda a su yerno, además de que siempre había insistido en que se restablecieran buenas relaciones con él.

Faltan datos, pero cabe deducir que la reacción concejil, tras haber rechazado de plano en los comienzos de este año el acuerdo de San Esteban del Puerto, sería la de plegarse a las circunstancias, porque un periodo de transición y la certidumbre de que don Juan Manuel alcanzaría un lugar destacado en la nueva regencia que habría de formarse en tanto se prolongase la menor edad de Alfonso XI, les obligaba a adelantarse a posibles represalias, por lo que, en Enero de 1320, Gil de Moncada, Berenguer Pujalte y Bernat Mena, enviados de Murcia, se presentaron ante don Juan Manuel y le mostraron la predisposición del concejo murciano a reconocerlo como adelantado. Ahora el señor de Villena podía poner sus condiciones: entrada libre en la ciudad, obediencia a quien designara como su lugarteniente en el adelantamiento, que debía ser vasallo real, y pago de las rentas que se le debían por la tenencia de los castillos a su cargo.

Los murcianos aceptaron y también mostraron su aquiescencia a la jefatura de Alfonso Fernández de Biedma, designado adelantado por don Juan Manuel. En Octubre de este mismo año representantes concejiles, encabezados por Fernández de Biedma, acudieron a Valladolid ante la reina doña María de Molina para obtener la confirmación de sus privilegios y con ella la carta de perdón general por todo cuanto había sucedido en Murcia desde la muerte de Fernando IV hasta la del infante don Pedro. Así se hizo y la abuela del rey, en nombre del monarca, expidió el documento en el que hacía constar todos los hechos tan reiteradamente expuestos en el orden del día de todos los fracasados conciertos de los años anteriores: adelantamiento, «fuera echados", destrucción del alcázar, aprobación de los acuerdos concejiles, sentencias de los alcaldes y todas las demás cuestiones. Sagaz, la reina, encontró una base político-jurídica para exculpar a los murcianos de todo lo pasado y, en nombre de su nieto, decía: «Este perdon les fago yo porque sope yo por cierto que esto que los de Murcia fizieron, que lo fizieron por mandado del infante don Pedro, mio tio e mio tutor, que Dios perdone». Por el bien de todos, reina y madre, hacía recaer en su difunto hijo toda la responsabilidad de lo pasado, era fórmula precisa para la pacificación y convivencia murciana.

En el mes de Noviembre se desplazaron los mismos representantes murcianos a Córdoba con objeto de entrevistarse con don Juan Manuel, que se titulaba ya tutor de 
Alfonso XI y adelantado del Reino de Murcia y, el día 30, mediante juramento solemne, poniendo la mano derecha sobre la Cruz y los Evangelios, prometió olvido de todas las querellas y demandas que podía tener contra la ciudad y sus vecinos, porque, según escribiría, quería poner paz y sosiego en las ciudades y lugares que le habían reconocido como tutor, así como también recordando los servicios que Murcia había prestado a su padre y a él mismo tiempo antes.

En los días siguientes atendió diversas peticiones concejiles y un cuaderno en que se solicitaban innovaciones jurídicas necesarias por no estar contenidas en el Fuero y privilegios de la ciudad. Finalmente, el 10 de Diciembre, todavía en Córdoba, hacía constar que se mantenía en todo lo referente a los acuerdos concertados con el infante don Pedro en San Esteban del Puerto, si bien con ciertas excepciones concernientes al gobierno de la ciudad, volver al régimen mantenido en el reinado de Fernando IV, esto es, no sólo ya la vuelta de los "fuera echados", sino la configuración del órgano concejil que el había establecido, la de sus vasallos y adictos.

Pero la historia de Murcia en el período comprendido entre 1321 y 1325 , al que hay que agregar un apéndice de dos años, puesto que en 1327 se resolvería toda la problemática mantenida por Murcia y don Juan Manuel durante trece años, es prácticamente desconocida. Un silencio casi impenetrable impide conocer hechos, vicisitudes, nombres y desenvolvimiento del concejo en estos cinco años, así como aspectos económicos, demográficos y, en general, el desarrollo de la ciudad en este espacio de tiempo. Sí que se mantenía la inseguridad fronteriza con frecuentes incursiones de almogávares granadinos hasta la firma de la paz de 1321, primero por cinco años y después ampliada por el monarca nasrí a siete, lo que despertó el recelo Pedro López de Ayala por si tenía consecuencias para Aragón, que sólo la había concertado por cinco años, pero la vigencia de la tregua no significaría la desaparición completa de las incursiones de los adalides granadinos. En orden distinto cabe señalar la celebración de un Sínodo Diocesano convocado por el obispo Juan Muñoz Gómez de Hinojosa en 1323, en el que se promulgó un Catecismo, el mismo que Guillermo de Gudín, cardenal de Santa Sabina, aprobó el año anterior en el Concilio de Valladolid, con el doble objetivo de reforma del clero y de costumbres.

A la muerte de María de Molina, el infante don Felipe, don Juan Manuel y don Juan, hijo del infante don Juan, se repartieron el gobierno de Castilla en las zonas geográficas donde habían logrado imponerse y se les mantuvieron adictas. Todo ello en un continuado y largo periodo anárquico, donde el desorden, robos, extorsiones y asaltos se sucedían en todos los reinos de la corona castellana, cuya narración por la Crónica resulta estremecedora y evocadora de los calamitosos años que siguieron a la muerte de Fernando IV y que cabría resumirlo en las palabras que un enviado de Jaime II utilizó para concretar el panorama político castellano: «Todos entre si pugnan por destruirla, que quien mas puede mas lleva e quien menos, lazra (lacera, destruye) e non saben que es justicia nin les place con ella».

Un suceso, que en don Juan Manuel no es insólito y que comenta Giménez Soler, fue una curiosa misiva que Bernardo de Sarriá envió a Jaime II en la que le relataba una doble propuesta del tutor de Alfonso XI, en fechas cercanas a la mayor edad del 
rey. Don Juan Manuel se hacía eco de una supuesta conjura que mantenían algunos consejeros del joven monarca para cuando alcanzara la mayoría de edad, pretendiendo hacerle ver la obligación que tenía de recuperar la parte del Reino de Murcia anexionada a la Corona de Aragón por la sentencia de Torrellas. Y para evitar lo que podía derivar en guerra entre los dos estados, don Juan Manuel proponía concertar el matrimonio de una hija de Jaime II con el monarca castellano y que la infanta llevara como dote dicho territorio, con lo que la paz quedaba asegurada; también, como fiel servidor que se declaraba de su suegro, le sugería la prestación de dos galeras con sus jarcias que don Jaime tenía en Valencia, pues acababa de terminar de pagar la compra de Cartagena, vendida por Pedro López de Ayala, y con ellas, más una nave de tres cubiertas y dos leños armados que estaban en el puerto cartagenero, podría ayudarle en caso de guerra con Castilla. Quien esto decía era por entonces tutor de Alfonso XI y recibió por respuesta un rechazo a tan desmedida propuesta matrimonial, pues Jaime II dejó bien claro que no cedería ni una alquería de la tierra de Murcia que mantenía con justo título y dejó la cuestión de las dos galeras para un tiempo futuro que no llegaría nunca.

Dos hechos que se sucedieron en Murcia en este mismo año 1325 son exponentes de la tensión y situación insostenible en la que se hallaban los vecinos de Murcia y que agotaría su paciencia ante las exigencias e injusticias de quienes gobernaban la ciudad en nombre de don Juan Manuel. Una tumultuosa rebelión, de la que salió mal herido Sancho Sánchez de Lariega, a quien Jaime II denomina caballero de don Juan Manuel y que era teniente de adelantado de Pedro López de Ayala. El rey de Aragón, por carta fechada en 18 de Febrero, se dirigía a éste para conocer lo ocurrido y en ella habla de «ayuntamiento, alboroço e bullicios e asonamientos fechos en la ciudad contra vos por aquellos que fizieron las dichas feridas". La situación conflictiva, estallido de un odio contenido durante mucho tiempo, pudo ser dominada; pero cuando, meses más tarde, se recibió en Murcia la carta de Alfonso XI en la que notificaba su mayoría de edad y prohibía que se cumplieran las cartas de quienes habían sido sus tutores, el cese de la minoría fue interpretado a que cesaba también el adelantamiento, por lo cual, según carta posterior de Alfonso XI, «alborotaron el pueblo e fezieron conçejo e revocaron las cosas que el dicho don lohan avia fecho". Se restablecería el orden, aunque le costó a Pedro López de Ayala su destitución como lugarteniente de don Juan Manuel en el adelantamiento.

El suceder murciano en estos años tiene un resumen sustancioso en las cartas reales de los años 1325 y 1327, en las don Alfonso se hacía eco de las quejas y querellas expresadas por los enviados murcianos quienes, pese a que don Juan Manuel mantenía su alta posición política en la corte, acrecentada con el compromiso matrimonial de su hija, acudieron a las Cortes de Valladolid, cosa que el señor de Villena no pudo impedir, y allí, ante los ojos y oídos de los asistentes, mostraron sus agravios y quejas, todas ellas escuchadas y aceptadas como verdaderas, que fueron el origen de las disposiciones del rey para poner fin a tal situación, pero su reiteración y exigencias de su cumplimiento muestran su ineficacia al mantenerse el concejo restringido creado por don Juan Manuel y continuar éste como adelantado mayor. 
En estas cartas se hace mención de hombres buenos expulsados de la ciudad por orden de don Juan Manuel, otros alejados por temor a ser muertos; algunos denunciaban su estancia en Orihuela, faltos de bienes y con miedo al regreso. Aún más, se ordenó por pregón salir de la capital y villas del reino a una lista cualificada de vecinos y, tiempo después, nuevos pregones los emplazaban a comparecer ante los tutores en la corte, a la que no acudieron por el peligro y gastos de desplazamiento y por considerar que no se les haría justicia, por lo que sus ausencias darían lugar a las sentencias que decretaban la pérdida de sus bienes. La veracidad de todo sería reconocida por Alfonso $\mathrm{XI}$ : "sabiendo yo que esto que ellos querellan que es notorio e manifiesta cosa».

La contienda Murcia-don Juan Manuel termina en 1327 cuando el señor de Villena se rebeló por la ruptura del compromiso matrimonial de su hija y retenerla el rey en su poder. Sería entonces cuando Alfonso XI reconocería en toda su amplitud las denuncias murcianas: «En tienpos pasados los mas caualleros e escuderos e muchos otros omnes se fezieron vasallos e acostados de don Johan, fijo del infante don Manuel, e con el poder del dicho don Johan todos los fechos de la çibdad auien de pasar por su mano e con esto catauan mas por seruiçio del dicho don Johan, por conplir su talante, que non por el mio seruiçio ni por de vosotros, e que antes se cunplie en Murçia e en el regno las cartas e mandado de don Johan, que las cartas e mio mandado".

$Y$ como punto y final, comenzaba el retorno. El 10 de Octubre de 1327 se presentaba ante el concejo de Murcia Fernán Alfonso, hijo de Rodrigo Alfonso de Magaz, portando una carta real para que lo acogieran en la ciudad, porque siendo vasallo de don Juan Manuel «partiose del dicho don Johan e vinose para mi merçed e es mio vasallo"; sería el primero de una curiosa lista de vasallos y "acostados" del señor de Villena que, en grupo o individualmente, fueron presentándose en los meses e incluso años siguientes con igual solicitud. Se cumplía de esta manera el ordenamiento concejil, ratificado por el rey, por el que se establecía que en Murcia sólo podían vivir y ser vecinos de ella los vasallos reales exclusivamente. Comenzaba un nuevo período histórico de la ciudad de Murcia y su Reino.

Todo daría un vuelco en 1327, año que afectó profundamente a don Juan Manuel. Murió su esposa, Constanza de Aragón; también su suegro, el rey Jaime II; se hace público el nuevo compromiso matrimonial de Alfonso XI con María de Portugal y ve como su hija, no sólo no sube al trono castellano, sino que queda bajo la custodia de su soberano. Un cambio profundo ante la realidad histórica a la que se enfrentaría colérico, amargado y otra vez a la lucha desesperada, destructiva y a la larga inútil.

Hombre de acción, con frecuencia irreflexiva, contradictorio entre su forma de pensar y obrar, sería a raíz de su fracaso político cuando más humano, junto a su incansable actividad político-bélica, tendrá tiempo para atender al bienestar de sus obedientes vasallos del señorío de Villena; también para leer, traducir, reflexionar y exponer por escrito variedad de temas literato-políticos, que señalarían vías de gobierno, de razón de Estado propias de su prosapia y condición, de lo que realmente pensaba pero que por sus ambiciones había combatido y erosionado en años de lucha y expectativa por gozar del poder. Una obra que lo inmortalizaría, haría olvidar su actividad política y lo situaría en la cumbre de la literatura castellana medieval. 